\title{
TODA ESTÓRIA É UMA NARRATIVA? \\ GÊNEROS DE TEXTO EXEMPLUM E EPISÓDIO \\ EM LIVRO DIDÁTICO DE LÍNGUA PORTUGUESA'
}

\author{
IS EVERY STORY A NARRATIVE? \\ EXEMPLUM AND ANECDOTE GENRES \\ IN PORTUGUESE TEXTBOOKS
}

\section{Carla Carine Gerhardt ${ }^{*}$ Cristiane Fuzer ${ }^{* *}$}

\section{RESUMO}

Ao ler ou ouvir uma história ou uma estória, é natural a associação de sua organização textual à narrativa no contexto brasileiro. Entretanto, se levadas em conta determinadas características linguísticas que evidenciam o propósito sociocomunicativo e as etapas de gênero dos textos, nem sempre histórias ou estórias são contadas fazendo uso da narrativa. Para evidenciar isso, neste estudo, objetivamos apresentar características linguísticas que instanciam outros gêneros de texto usados para envolver ouvintes ou leitores, encontrados em livros didáticos de língua portuguesa. Tendo em vista a abordagem de gênero da Escola de Sydney (MARTIN e ROSE, 2008), utilizamos princípios da Linguística SistêmicoFuncional (LSF), com foco no sistema léxico-gramatical de transitividade (HALLIDAY; MATTHIESSEN, 2004, 2014) e no subsistema de Atitude do sistema semântico-discursivo de Avaliatividade, (MARTIN, WHITE, 2005). Para análise, foram selecionados, nos livros didáticos "Português Linguagens" (CEREJA; MAGALHÃES, 2012) e "Projeto Teláris Português" (BERTIN; BORGATO; MARCHEZI, 2012), 21 textos com potencial para instanciar os gêneros exemplum e episódio, tendo em vista propósitos sociocomunicativos específicos, a estrutura esquemática e características linguísticas típicas de cada gênero de texto. A análise dos componentes oracionais da transitividade e das ocorrências de avaliações de Atitude em cada texto evidenciou 8 instanciações de exemplum e 13 de episódio. Nas instanciações de ambos os gêneros, foram identificadas orações materiais e relacionais para introduzir personagens nas fases cenário e descrição, as quais constituem a etapa Orientação. As diferenças situam-se no modo como o problema é respondido nas etapas: com Reação no episódio e Interpretação no exemplum. Além disso, para cumprir o propósito

\footnotetext{
* Universidade Federal de Santa Maria, UFSM, Santa Maria, RS, Brasil. carla.gerhardt@hotmail.com Orcid: https://orcid.org/0000-0002-5603-7916

** Universidade Federal de Santa Maria, UFSM, Santa Maria, RS, Brasil. crisfuzerufsm@gmail.com Orcid: https://orcid.org/0000-0001-9499-6838

1. O presente trabalho foi realizado com apoio da Coordenação de Aperfeiçoamento de Pessoal de Nível Superior - Brasil (CAPES).
} 
de cada gênero, as instanciações de exemplum apresentam mais avaliações de julgamento, enquanto as de episódio apresentam avaliações de afeto.

Palavras-chave: gêneros de texto da família das estórias; sistema semântico-discursivo de Avaliatividade; sistema léxico-gramatical de Transitividade.

\section{ABSTRACT}

When reading or listening to or a history or a story, it is natural to associate its textual organization with narrative in Brazilian context. However, if one takes into account certain linguistic characteristics that show the socio-communicative purpose and the genres stages, stories and histories are not always told using narrative. In order to demonstrate these aspects, in this study, we aim to present linguistic characteristics that instantiate other genres of text used to engaging listeners or readers in Portuguese language textbooks. Based on the Sydney School genre approach (MARTIN and ROSE, 2008), we use the principles of Systemic-Functional Linguistics (SFL), focusing on the lexical-grammatical system of transitivity (HALLIDAY and MATTHIESSEN, 2004, 2014) and on the Attitude subsystem of the semantic-discursive system of Appraisal (MARTIN and WHITE, 2005). For the analysis, 21 texts with the potential to instantiate the exemplum and anecdote genres were selected in the Portuguese textbooks Português Linguagens (CEREJA; MAGALHÃES, 2012) and Projeto Teláris - Português (BERTIN, BORGATO; MARCHEZI, 2012), considering their specific sociocommunication purposes, their schematic structure and typical language characteristics of each genre. The analysis of the transitivity components and the attitude occurrences in each text showed 8 instances of exemplum and 13 anecdotes. In the instantiations of both genres, material and relational clauses were identified to introduce characters into the scenario and description phases, which constitute the Orientation stage. The differences lie in the way the problem is answered in the steps: with Reaction in the anecdote and Interpretation in the exemplum. In addition, to fulfill the purpose of each genre, exemplum instantiations present more judgments, while those of anecdote have evaluations of affect.

Keywords: Family Genres of Stories; Semantic-Discursive System of Appraisal; LexicalGrammatical System of Transitivity.

\section{INTRODUÇÃO}

Sempre que se lê ou se ouve uma história ou mesmo uma estória² ${ }^{2}$ é comum a associação de sua organização textual à narrativa. Frequentemente, fábulas,

2. Embora seja corrente o uso da palavra "história" para se referir a textos que compartilham experiências reais ou imaginárias, com ou sem compromisso com os fatos, em livros didáticos, artigos acadêmicos e documentos oficiais, atendendo a recomendações dos dicionários de língua portuguesa, tendo em vista a perspectiva teórica de gênero de texto adotada neste trabalho, explicada na seção 2.1, consideramos necessária a distinção funcional entre "histórias" e "estórias". Por isso, quando nos referirmos a textos que têm por propósito documentar eventos socialmente relevantes (compromisso com fatos), usamos o termo "história" (bistory), e quando nos referimos a textos que têm por propósito compartilhar experiências reais ou imaginárias para entretenimento (sem compromisso com fatos em sua totalidade), usamos o termo "estória" (story), sendo esse segundo caso o foco do presente estudo. 
anedotas, piadas, contos são classificados como textos narrativos, especialmente no contexto escolar. Prova disso são enunciados como estes, extraídos de livros didáticos de língua portuguesa recomendados pelo Programa Nacional do Livro Didático triênio 2014-2016:

Leia a fábula a seguir, observando o modo como o texto está organizado na página.

A mosca e a formiga [...]

Nos textos narrativos, há geralmente várias vozes. Uma delas é o narrador. [...] Identifique no primeiro parágrafo do texto o trecho que corresponde à voz do narrador. (CEREJA; MAGALHÃES, 2012, p. 103-104, grifo nosso).

Identifique no conto "O bisavô e a dentadura" os parágrafos correspondentes a cada um dos momentos da narrativa. (BORGATTO, BERTIN, MARCHEZI, 2012, p. 24, grifo nosso)

Estudos realizados com aporte teórico da Linguística Sistêmico-Funcional (doravante LSF), entretanto, têm mostrado que nem todos os textos que têm por propósito compartilhar experiências reais ou imaginárias numa sequência espaciotemporal são, de fato, narrativas - se levadas em conta determinadas características linguísticas que evidenciam o propósito sociocomunicativo e as etapas de gênero. Tais estudos, desenvolvidos desde a década de 1980 por Martin e sua equipe, mapearam gêneros de textos usados no contexto escolar australiano, dentre os quais estão as narrativas ao lado de outras maneiras de compartilhar experiências e eventos.

Ao buscarem aplicar especificamente às estórias (stories) produzidas na escola a estrutura esquemática da narrativa, conforme proposta por Labov e Valetsky (1967), para as narrativas de experiência pessoal ${ }^{3}$, Plum (2004) percebeu que, no contexto australiano, nem todas apresentavam resolução. Muitas apenas relatavam uma sequência de eventos, outras compartilhavam emoções vivenciadas por personagens, outras julgavam comportamentos atribuídos a personagens, sem que a complicação anunciada fosse resolvida.

Em vista dessa constatação, os pesquisadores da abordagem que ficou conhecida como Escola de Sydney, fazendo uso de pressupostos da teoria sistêmicofuncional de Halliday $(1978,1989)$, identificaram que, embora compartilhassem um mesmo propósito geral (envolver ou entreter o leitor), algumas estórias apresentavam regularidades linguísticas que realizavam propósitos sociocomunicativos mais específicos, que possibilitavam classificar tais textos como instâncias ${ }^{4}$ de gêneros

3. As etapas para a narrativa são: (Resumo) ^ (Orientação) ^ Complicação ^ Avaliação ^ Resolução ^ (Coda). Os parênteses indicam as etapas opcionais, e o símbolo $\wedge$ significa sequência.

4. Para Hasan (2009, p. 169), a instanciação é "a relação entre um potencial e sua instância" e, segundo Halliday (2009, p. 63), "cada texto é uma instância de algum sistema da linguagem". 
distintos. Sob esse raciocínio, verificaram uma diferença básica entre a narrativa e outras estórias: a presença da etapa resolução e uma variedade de tipos de avaliação (afeto, julgamento e apreciação) (MARTIN e ROSE, 2008).

Após uma série de análises conduzidas pelos pesquisadores envolvidos no projeto The Write it Right e, mais recentemente, no programa Reading to Learn (ROSE e MARTIN, 2012), foram sistematizadas as etapas e as principais características linguísticas que possibilitam agrupar as estórias em uma mesma família, mas descrevê-las como gêneros de texto distintos, como buscamos esclarecer na seção 2 deste artigo, na qual apresentamos o aporte teórico que norteia o estudo aqui apresentado.

Em contraponto com outras famílias de gêneros, como das histórias (bistories), dos procedimentos, dos relatórios, das explicações, das reações a textos e dos argumentos, os gêneros da família das estórias, conforme Martin e Rose (2008), são considerados "elementares", assim denominados por apresentarem linguagem menos elaborada, aparecendo como os primeiros a serem estudados no início da escolarização, como "andaimes" (nos termos de Vygotsky, 1984), para depois partir para gêneros mais elaborados, de linguagem mais concisa, constituída de metáforas, por exemplo. Esses gêneros da família das estórias circulam em várias culturas, letradas ou não, conhecidas, sob esse viés, por qualquer criança ingressante na escola.

Olhando para o contexto escolar brasileiro - e uma janela que se tem considerado pertinente para isso são os livros didáticos distribuídos nas escolas -, têm-se desenvolvido estudos que buscam evidenciar quais gêneros de texto, em língua portuguesa, são usados para engajar leitores em nossa cultura, tendo por base princípios da Gramática Sistêmico-Funcional de Halliday e seus desdobramentos para a abordagem sociossemiótica de gêneros proposta pelos pesquisadores de Sydney (MARTIN, 1984; PLUM, 2004; MARTIN e ROSE, 2008; CHRISTIE e DEREWIANKA, 2008; ROSE e MARTIN, 2012, dentre outros). Um levantamento de estudos prévios indica que, dentre os gêneros de texto da família das estórias, a narrativa possui ampla literatura sobre sua constituição, seja no âmbito mundial, seja no nacional, não só na área da linguagem, como também na psicologia e sociologia. Dentre os estudos com foco na língua inglesa, destacamos os trabalhos de Rothery (1990), Martin (1997), Ochs (1997), Plum (2004), Christie e Derevianka (2008). No Brasil, encontramos estudos de Cunha (1997), Bastos e Biar (2015), Souza (2016), Martino (2016), Melo (2017), dentre outros, sob diferentes perspectivas teóricas. 
Sobre narrativas analisadas na perspectiva sistêmico-funcional, alguns estudos têm sido produzidos em decorrência do projeto de ensino e extensão Ateliê de Textos, da Universidade Federal de Santa Maria (UFSM): Fuzer, Gerhardt e Weber (2016) analisam etapas e fases da narrativa em "O Pequeno Polegar"; Fuzer e Weber (2018) analisam instanciações de gêneros em três versões diferentes "Chapeuzinho Vermelho". No projeto, foi produzido, inclusive, um caderno didático (FUZER, 2016) que utiliza o Ciclo de Ensino e Aprendizagem para trabalhar com leitura e escrita de narrativas nos anos finais do ensino fundamental.

No presente artigo, focalizamos, à luz da Linguística Sistêmico-Funcional, instâncias de outros dois gêneros da família das estórias: exemplum e episódio. A escolha pelo exemplum, muito comum em fábulas presentes nos livros didáticos, devese, sobretudo, ao propósito específico de julgar comportamentos, desempenhando um papel importante no processo de ensinar valores. Nesse sentido, o exemplum vai ao encontro das orientações dos PCN's para a Língua Portuguesa (BRASIL, 1998), que solicitam o trabalho com valores em qualquer disciplina do currículo escolar. $\mathrm{O}$ episódio, por sua vez, cujo propósito é compartilhar emoções, é muito frequente em piadas, conforme estudo de Fuzer, Castro e Gerhardt (2016) em livro didático de língua portuguesa para o $6^{\circ}$ e o $7^{\circ}$ ano do ensino fundamental. Nesse sentido, o episódio contribui para tornar o ensino mais lúdico, aspecto que vem obtendo importância no contexto de ensino brasileiro (COSTA; CATTELAN, 2010). De todo modo, muito ainda precisa ser pesquisado e descrito sobre esses dois gêneros de texto no contexto escolar brasileiro para se aproximar da produção do que já existe, por exemplo, sobre a narrativa.

Nesse sentido, o presente estudo tem por objetivo apresentar características linguísticas que instanciam outros gêneros de texto, para além da narrativa, usados para contar estórias, encontrados em livros didáticos de língua portuguesa. Esse objetivo envolve verificação do propósito sociocomunicativo, da estrutura esquemática de gênero (doravante EEG) e de características linguísticas, com foco no sistema léxico-gramatical de transitividade (HALLIDAY e MATTHIESSEN, 2004, 2014) e no sistema semântico-discursivo de Avaliatividade, especialmente do subsistema de Atitude (MARTIN e WHITE, 2005), realizado, principalmente, pelo sistema léxico-gramatical de transitividade, apresentados na seção 2.

Para isso, desenvolvemos uma metodologia de análise, descrita na seção 3, que contempla as perspectivas topológica e tipológica, conforme Martin e Rose (2012), para evidenciar semelhanças e diferenças entre os textos com potencial para instanciação dos gêneros de texto exemplum e episódio. Os resultados estão apresentados na seção 4, em que são sistematizados aspectos contextuais e 
linguísticos tipicamente usados para instanciar o propósito sociocomunicativo de cada um desses gêneros.

\section{ABORDAGEM DE GÊNERO DE TEXTO NA LINGUÍSTICA SISTÊMICO-FUNCIONAL}

A abordagem de gêneros de texto da perspectiva sistêmico-funcional traz contribuições aos estudos da linguagem em contexto escolar no sentido de tornar o trabalho de análise mais seguro, já que a teoria oferece ferramentas de análise que possibilitam tornar explícitos elementos linguísticos que realizam os sistemas, o contexto e o propósito social dos textos. Hyland (2004) expõe os benefícios da explicitação que aspectos linguísticos da LSF fornecem à identificação e ao entendimento do contexto em instanciações de gênero:

[...] esta explicitação dá aos professores e alunos algo para alcançarem, uma 'pedagogia visível' que deixa claro o que é para ser aprendido, ao invés de confiar em métodos indutivos de acerto ou erro, segundo os quais se espera que os alunos adquiram os gêneros de que precisam a partir da crescente experiência de repetição ou anotações do professor ${ }^{5}$ (HYLAND, 2004, p. 11).

Especificamente sobre gêneros de texto, o autor aponta que os estudantes, para ler e escrever um texto adequado a uma situação comunicativa, precisam conhecer como cada gênero é organizado e quais são os padrões léxico-gramaticais tipicamente usados para expressar significados (HYLAND, 2004). Desse modo, o texto, como instância do sistema linguístico, apresenta pistas sobre o contexto em que foi produzido, ao mesmo tempo em que o conhecimento do contexto facilita a compreensão dos significados que constituem o texto (HALLIDAY, 1989).

\subsection{Gênero e registro}

$\mathrm{Na}$ perspectiva sistêmico-funcional, os textos variam de acordo com a natureza dos contextos em que são usados. No contexto de situação, os textos variam conforme os registros, que são padrões de instanciação do sistema (HALLIDAY e MATTHIESSEN, 2014), ou "as provas dos fatos" (GERHARDT, 2017). No contexto de cultura, esses padrões se aproximam e formam as famílias de gêneros conforme os propósitos sociocomunicativos que compartilham.

5. As traduções neste artigo são de responsabilidade das autoras. No original: This explicitness gives teachers and learners something to shoot for, a "visible pedagogy" that makes clear what is to be learned rather than relying on hit-or-miss inductive methods where by learners are expected to acquire the genres they need from the growing experience of repetition or the teacher's notes. 
Para Halliday e Matthiessen (2008), a linguagem é entendida como "um recurso para fazer sentido" 6 (p. 3), que ocorre a partir de seleções aplicadas em contexto de uso. Sob esse pressuposto, um sistema é instanciado em determinado contexto a partir de escolhas, dando origem ao objeto sistêmico-funcional de estudo da linguagem: o texto, que é o registro de determinadas escolhas possíveis dentro de determinado contexto.

Ainda segundo os autores, o contexto organiza-se a partir de duas facetas, uma de um ambiente de comunicação específico, o contexto de situação, e outra mais ampla, que abarca a formação cultural geral em que a mesma interação acontece, o contexto de cultura. Halliday (1989) propôs três variáveis para análise do contexto de situação: o campo, as relações e o modo.

Conforme Halliday e Matthiessen (2014), o campo diz respeito à atividade desenvolvida pelo discurso, ao que está acontecendo, à natureza da situação. A variável relação refere-se a quem está participando da situação, aos papéis desempenhados, ao status, ao distanciamento e/ou avaliação entre esses participantes da interação e ao valor imbuído no domínio da comunicação. O modo, por sua vez, é a variável responsável por organizar a linguagem na situação: a orientação do texto em direção ao campo e às relações, o modo retórico, o discurso, o meio e o canal.

De acordo com Gouveia (2013), se na análise do contexto de situação algumas características do registro se repetirem, verificar-se-ão instanciações de padrões, que podem constituir e delimitar determinado gênero em alguma cultura. Contudo, estudos sobre a verificação da cultura nos textos para identificação de gêneros de texto na perspectiva sistêmico-funcional ainda estão em processo de construção na literatura e, nesse sentido, a investigação aqui empreendida busca revelar padrões de uso da língua portuguesa em textos que circulam no contexto escolar brasileiro, tendo como ponto de partida referenciais já existentes, como os de Martin e Rose (2008) e Rose e Martin (2012).

Os gêneros de texto podem ser entendidos tanto em sua organização tipológica quanto topológica (MARTIN e ROSE, 2008). Na organização tipológica, os gêneros são entendidos em distintos tipos de etapas, fases e propósitos. Essa representação costuma "considerar as semelhanças e diferenças entre os gêneros" (MARTIN, 2000, p. 13). Por outro lado, na perspectiva topológica, os gêneros possuem características que aproximam os textos (GOUVEIA, 2013). Por exemplo, vários textos com propósito, etapas e escolhas léxico-gramaticais semelhantes e recorrentes podem ser representativos de um gênero na cultura.

6. a resource for making meaning.

7. [...] to factor out similarities and differences among genres. 
$\mathrm{Na}$ Linguística Sistêmico-Funcional, gênero de texto é definido atualmente como "processo social organizado por etapas e orientado para propósitos sociais" ${ }^{18}$ (MARTIN; ROSE, 2008, p. 8). Os gêneros são organizados em famílias, a partir de um propósito mais amplo, em que, por exemplo, a família das estórias (stories) possui o propósito de envolver o leitor; a das histórias (bistories), de registrar fatos históricos; a dos procedimentos, de instruir; a dos argumentos, de avaliar, e assim por diante. Cada família, por sua vez, abriga gêneros com propósitos específicos.

$\mathrm{Na}$ sequência, exploramos um pouco mais as características da família das estórias (stories), termo usado na teoria sistêmico-funcional para agrupar textos que diferem em propósito, estrutura e padrões linguísticos em relação à família das histórias (bistories), que abriga gêneros cujo propósito é documentar, explicar ou interpretar fatos com relevância social. Na língua portuguesa, essa distinção é reconhecida por alguns autores, como Nelly Novaes Coelho (2010), para quem, "em diferentes estilos, formas ou linguagens [...], a invenção literária atual oferece às crianças estórias atraentes, vivas e bem-humoradas que buscam diverti-las e, ao mesmo tempo, estimular-lhes a consciência crítica em relação aos valores" (COELHO, 2010, p. 286, grifo nosso).

\subsection{Gêneros da família das estórias}

$\mathrm{Na}$ família das estórias, foco deste estudo, aparecem os gêneros relato, narrativa, notícia, observação, episódio e exemplum. Segundo Martin e Rose (2008), há uma sequência de encadeamento de etapas em gêneros, em que uma etapa constrói a outra a fim de alcançar o propósito do gênero. Acerca do propósito e das etapas dos gêneros, Rose (2014) explica que "episódios e exempla diferem das narrativas porque eles não têm resolução" (p.6). O Quadro 1 apresenta uma síntese quanto ao propósito e às etapas dos gêneros da família das estórias.

\section{Quadro 1. Propósitos e etapas de gêneros da família das estórias}

O propósito de um relato é contar uma série de eventos, de modo que suas etapas incluem uma Orientação e Registro de eventos.

O propósito de uma narrativa é, para os personagens centrais, resolver uma complicação, por isso as suas etapas incluem Orientação, Complicação e Resolução. Também há geralmente uma avaliação após a complicação, que expressa os sentimentos dos personagens sobre o que aconteceu.

8. No original: staged, goal oriented social processes. 
O propósito de um episódio é compartilhar sentimentos sobre um evento complicando, que não está resolvido. As etapas de um episódio incluem Orientação, Complicação e Avaliação, que avalia os sentimentos do narrador sobre o que aconteceu (embora a avaliação pode ser deixada implícita).

O propósito de um exemplum é julgar o caráter ou comportamento de uma pessoa. Suas etapas também incluem Orientação, Complicação e Avaliação, mas esta avalia caráter ou comportamento da pessoa. Episódios e exempla diferem das narrativas porque eles não têm resolução. Mas eles são tão comuns como narrativas.

O propósito de uma notícia é relatar ângulos em um evento interessante. As notícias não são sequenciadas no tempo. Em vez disso, notícias começam com um parágrafo de Lead que resume a estória, e, em seguida, volta a ela a partir de vários Ângulos.

Fonte: traduzido e adaptado de Rose $(2014$, p. 6).

Rothery e Stenglin (2000) verificaram que todos os gêneros da família das estórias apresentam a mesma etapa inicial, a Orientação, e que são as "etapas intermediárias" (p. 238) que definem os gêneros de texto. Martin e Rose (2008) acrescentam que a estória apresenta uma sequência de atividades esperadas, em que, por exemplo, personagens e lugares são apresentados em um fluxo natural de eventos. Contudo, nos gêneros em que a etapa Orientação é usada, essa expectativa é interrompida e o que distingue um gênero do outro, no critério estrutural, é a natureza dessa interrupção e como ela é respondida. Se o problema é resolvido, tem-se uma narrativa. Para o caso de não ser resolvido, há duas formas de resposta: se for uma interpretação, tem-se um exemplum; se for uma reação, tem-se um episódio.

Ademais, Martin e Rose (2008) e Rose (2013) apontam fases para caracterização dos gêneros da família das estórias (Quadro 2). Essas fases são mais maleáveis e podem aparecer de forma aleatória em qualquer gênero da família, ao contrário das etapas, que são fixas em cada gênero.

\section{Quadro 2. Fases em estórias}

\begin{tabular}{|l|l|}
\hline \multicolumn{1}{|c|}{ Fases } & \multicolumn{1}{c|}{ Funções } \\
\hline cenário & Apresenta o contexto (identidades, atividades, espaços) \\
\hline descrição & Evoca o contexto (traz à luz lembranças e respostas emocionais) \\
\hline eventos & Sucessão de eventos \\
\hline efeito & Resultado material \\
\hline reação & Resultado de comportamento e/ou atitude \\
\hline
\end{tabular}

9. "midlle stages". 


\begin{tabular}{|l|l|}
\hline problema & Tensão criada por contraexpectativa ("mas") \\
\hline solução & Fim da tensão criada por contraexpectativa \\
\hline comentário & Introdução do comentário do narrador \\
\hline reflexão & Introdução dos pensamentos dos participantes \\
\hline
\end{tabular}

Fonte: traduzido e adaptado de Martin e Rose (2008, p. 82).

Rose (2013) explica que "tipos de fases dependem do gênero do texto, bem como o seu campo, o que está em causa no texto. Etapas organizam a estrutura global de cada texto, mas as fases organizam como ela se desenrola dentro dessa estrutura global" (p. 5). Verifica-se, portanto, que uma ou mais fases constituem etapas, as quais realizam o propósito sociocomunicativo do gênero, que, por sua vez, destaca a família dentro de um contexto de cultura. O propósito e a estrutura global dos textos que instanciam determinado gênero são realizados pelo sistema linguístico, que, na LSF, é estratificado. Do estrato da léxico-gramática, focalizamos funções do sistema de transitividade, apresentadas em 2.3. Do estrato da semântica do discurso, são considerados campos semânticos do subsistema de Atitude do sistema de Avaliatividade, apresentada em 2.4.

\subsection{Sistema léxico-gramatical de transitividade}

O sistema de transitividade reúne recursos léxico-gramaticais para a "construção de um quantum de mudança no fluxo de eventos como uma figura" (HALLIDAY; MATTHIESSEN, 2014, p. 10) (de acontecer, fazer, sentir, ser, ter ou existir). Esse sistema, conforme os autores, atua "como uma condução de elementos centrados em um processo" (Idem). Esses elementos desempenham as funções de participantes e circunstâncias, que, junto com o processo, constituem a oração.

O sistema de transitividade possibilita, assim, a análise de representações de experiências no nível da oração, a qual organiza configurações de significados constituídas de processos, participantes e circunstâncias. Os processos podem ser materiais, mentais, relacionais, verbais, comportamentais ou existenciais. Os participantes variam e estão associados aos processos, podendo ser Ator, Meta, Experienciador, Fenômeno, Portador, Atributo, Comportante e Existente, por exemplo. As circunstâncias podem ser de diversos tipos, como de localização no tempo e espaço, modo, ângulo, dentre outros $^{10}$ (HALLIDAY; MATTHIESSEN, 2014).

10. Descrição detalhada dos tipos de orações com processos, participantes e circunstâncias que constituem o sistema de transitividade em língua portuguesa pode ser encontrada em Fuzer e Cabral (2004) e em Cunha e Souza (2011). 
Halliday e Matthiessen (2014) pressupõem algumas realizações de tipos de oração conforme o contexto de uso. Ao aproximar esses pressupostos à família das estórias, podemos citar a utilização dos processos materiais, que, por representarem eventos e ações, concorrem para constituir a sequência de eventos na estória. Outro exemplo são as orações mentais e verbais em fábulas que representam animais como dotados de consciência humana. Esse processo, como Rothery e Stenglin (2000) exemplificam, é comum no gênero exemplum, em que animais são usados para representar comportamentos humanos, numa forma de estória metafórica para ensinar crianças e adultos sobre valores e vida em sociedade.

\subsection{Sistema de Avaliatividade: subsistema Atitude}

A análise do sistema de transitividade também possibilitou identificar ocorrências do subsistema Atitude do sistema de Avaliatividade ${ }^{11}$ (MARTIN, WHITE, 2005). Neste trabalho, são analisadas ocorrências de afeto, julgamento e apreciação. O afeto "trata de recursos para interpretar reações emocionais" (p. 35), o julgamento concerne aos "recursos para avaliar o comportamento de acordo com vários princípios normativos" (p.35), e a apreciação "olha recursos para construir o valor das coisas, incluindo fenômenos naturais e semiose" (p.35). Martin e Rose (2008) pressupõem campos semânticos da Atitude fundamentais em cada gênero (Quadro 3).

Quadro 3. Subsistema de Atitude em gêneros da família das estórias

\begin{tabular}{|l|l|l|c|l|}
\hline INSTÂNCIA & EXPERIÊNCIA & RESPOSTA & EXPERIÊNCIA & ATITUDE \\
\hline Relato & Recordação & [prosódica] & - & Variável \\
\hline Episódio & Evento Marcante & Reação & - & Afeto \\
\hline Exemplum & Incidente & Interpretação & - & Julgamento \\
\hline Observação & Descrição de Evento & Comentário & - & Apreciação \\
\hline Narrativa & Complicação & Avaliação & Resolução & Variável \\
\hline
\end{tabular}

Fonte: traduzido de Martin e Rose $(2008$, p.53)

Os gêneros, episódio e exemplum, foco deste estudo, são identificados pela presença substancial de avaliações de afeto e julgamento, respectivamente, para corroborar a construção do propósito dos gêneros, compartilhar emoções e julgar comportamentos. Essas avaliações atitudinais, realizadas por funções léxico-

11. Um apanhado de estudos detalhados sobre o sistema de Avaliatividade em língua portuguesa podem ser encontrados em Vian Jr, Souza e Almeida (2010). 
gramaticais de transitividade, de acordo com Martin e Rose (2008), Rose e Martin (2012), Martin e White (2005), destacam-se na instanciação de gêneros família das estórias, o que justifica o recorte teórico apresentado para este estudo.

\section{METODOLOGIA}

\subsection{Universo de análise e critérios de seleção do corpus}

Para este trabalho, foram selecionadas as coleções didáticas "Português: Linguagens" (CEREJA; MAGALHÃES, 2012) e "Projeto Teláris - Português" (BERTIN; BORGATO; MARCHEZI, 2012) como universo de análise, por esses serem os livros mais distribuídos, respectivamente, nas escolas públicas municipais, estaduais e federais de Ensino Fundamental de Santa Maria, no triênio 20142016 do Programa Nacional do Livro Didático (PNLD), conforme estudo prévio (FUZER $;$ GERHARDT; CARGNIN, 2015). As coleções são compostas por quatro livros, uma para cada ano escolar $\left(6^{\circ}\right.$ ao $9^{\circ}$ ano). Delas, foram coletados textos sobre os quais havia questões de análise linguística que contemplassem conteúdos gramaticais e/ou discursivos, pois estes são os conteúdos que mais se aproximam dos sistemas aqui analisados (sistema léxico-gramatical de transitividade e sistema semântico-discursivo de Avaliatividade). Desses textos, foram selecionados aqueles com potencial para instanciar os gêneros exemplum e episódio, a partir da identificação do propósito da família das estórias (entreter o leitor) e do propósito específico de cada gênero: julgar comportamentos no caso do exemplum e compartilhar emoções no caso do episódio.

Com base nesses critérios, o corpus ficou constituído de 21 textos - 8 com potencial de instanciação do gênero exemplum e 13 com potencial de instanciação do gênero episódio, Cada um dos textos é referido com a inicial "PL", que significa "Português-Linguagens", ou "TL", que significa "Teláris", seguido dos números 6 ou 7 , referindo-se, respectivamente, aos volumes do $6^{\circ}$ ou $7^{\circ}$ ano, mais o número correspondente da estória, por exemplo: "E1", "E2", ... As estórias de 1 a 13 representam os textos com potencial para instanciar episódios, e as de 14 a 21, exempla (Quadro 4). 
Quadro 4. Textos dos LDs que constituem o corpus de análise

\begin{tabular}{|c|c|c|c|}
\hline Cod. & Título & Fonte citada nos LDs & $\begin{array}{c}\text { Denominação dada } \\
\text { pelos LDs }\end{array}$ \\
\hline PL6E1 & Verbos & $\begin{array}{l}<\text { http://criancas.uol.com.br/piadas/ } \\
\text { piadas_aula.jhtm }>\text {. Acesso em: } 12 \\
\text { jan. } 2010 .\end{array}$ & Anedota \\
\hline PL6E2 & Os meninos morenos & $\begin{array}{l}\text { ZIRALDO. Os meninos morenos - } \\
\text { com versos de Humberto Ak'abal. } \\
\text { São Paulo: Melhoramentos, 2004, } \\
\text { p. } 45-48 \text {. }\end{array}$ & Narrativa \\
\hline PL6E3 & VI & $\begin{array}{l}\text { A rua dos cata-ventos. São Paulo: } \\
\text { Globo (C) by Elena Quintana }\end{array}$ & Poema \\
\hline PL6E4 & Os tempos verbais & $\begin{array}{l}\text { ZIRALDO. As anedotinhas do } \\
\text { Bichinho da Maçã. 6. ed. São Paulo: } \\
\text { Melhoramentos. 1988. p. } 26 .\end{array}$ & Piada \\
\hline PL7E5 & Minha rua & Folha de S. Paulo, 8/3/2003. & Poema \\
\hline PL8E6 & "Sinal vermelho" & $\begin{array}{l}\text { BUCHWEITZ, Donaldo (Org.). } \\
\text { Piadas para você morrer de rir. Belo } \\
\text { Horizonte: Leitura, 2001. p. } 87 .\end{array}$ & Texto \\
\hline PL8E7 & "Moça do interior" & $\begin{array}{l}\text { Adaptada de BUCHWEITZ, } \\
\text { Donaldo (Org.). Piadas para você } \\
\text { morrer de rir. Belo Horizonte: } \\
\text { Leitura. 2001. p. 179. } \\
\end{array}$ & Piada \\
\hline PL8E8 & Sexa & $\begin{array}{l}\text { VERÍSSIMO, Luis Fernando. Festa } \\
\text { de criança. São Paulo: Ática, } 2000 . \\
\text { p. 19-19. }\end{array}$ & Crônica \\
\hline PL8E9 & Continho & $\begin{array}{l}\text { CAMPOS, Paulo Mendes. Crônicas } \\
\text { - Para gostar de ler. São Paulo: } \\
\text { Ática, 2007, v. 1, p. } 74 .\end{array}$ & Conto \\
\hline PL8E10 & "Advogado" & $\begin{array}{l}\text { BUCHWEITZ, Donaldo (Org.). } \\
\text { Piadas para você morrer de rir. Belo } \\
\text { Horizonte: Leitura, 2001. p. } 33 .\end{array}$ & Anedota \\
\hline PL9E11 & "O louquinho" & $\begin{array}{l}\text { Ziraldo. Adedotinhas do Bichinho } \\
\text { da Maçã. São Paulo: Melhoramentos, } \\
\text { 1988, p. 17-18. }\end{array}$ & Anedota \\
\hline PL9E12 & "Idioma" & $\begin{array}{l}\text { BUCHWEITZ, Donaldo (Org.). } \\
\text { Piadas para você morrer de rir. Belo } \\
\text { Horizonte: Leitura, 2001. p. } 180 .\end{array}$ & Piada \\
\hline TL9E13 & Tapa-buracos & $\begin{array}{l}\text { Adaptado de Almanaque de Cultura } \\
\text { Popular. São Paulo: Andreato, n. } 97 .\end{array}$ & Piada \\
\hline
\end{tabular}




\begin{tabular}{|c|c|c|c|}
\hline PL6E14 & A mosca e a formiguinha & $\begin{array}{l}\text { LOBATO, Monteiro. Fábulas } \\
\text { e histórias diversas. São Paulo: } \\
\text { Brasiliense, 1960, p. 91-2. Monteiro } \\
\text { Lobato - Todos os direitos } \\
\text { reservados. }\end{array}$ & Fábula \\
\hline PL6E15 & O urso e a raposa & $\begin{array}{l}\text { ESOPO. Fábulas. Compilação de } \\
\text { Russel Ash e Bernard Higton. São } \\
\text { Paulo: Companhia das Letrinhas, } \\
\text { 1994. p. } 57 .\end{array}$ & Texto \\
\hline PL6E16 & O sapo e o escorpião & $\begin{array}{l}\text { PRIETO, Heloísa. O livro dos } \\
\text { medos. São Paulo: Companhia das } \\
\text { Letrinhas, 1998. p. } 25 .\end{array}$ & Fábula \\
\hline PL7E17 & O cão, o galo e a raposa & $\begin{array}{l}\text { ESOPO. Fábulas. Porto Alegre: } \\
\text { L\&PM, 1997, p. } 103 .\end{array}$ & Fábula \\
\hline PL7E18 & A toupeira & $\begin{array}{l}\text { ESOPO. Fábulas. Porto Alegre: } \\
\text { L\&PM, 1997. p. } 115 .\end{array}$ & Texto \\
\hline PL7E19 & O escularápio & $\begin{array}{l}\text { : FERNANDES, Millôr. Fábulas } \\
\text { Fabulosas. 12. ed. Rio de Janeiro: } \\
\text { Nórdica, 1991. p. 83-84. }\end{array}$ & Texto \\
\hline PL7E20 & A verdade na mata & $\begin{array}{l}\text { FERNANDES, Millôr. Fábulas } \\
\text { Fabulosas. 12. ed. Rio de Janeiro: } \\
\text { Nórdica, 1991. p. } 23 .\end{array}$ & Texto \\
\hline PL8E21 & Maneira de amar & $\begin{array}{l}\text { FERNANDES, Millôr. Fábulas } \\
\text { Fabulosas. 12. ed. Rio de Janeiro: } \\
\text { Nórdica, 1991. p. } 23 .\end{array}$ & Texto \\
\hline
\end{tabular}

\subsection{Procedimentos de análise}

O primeiro procedimento consistiu na descrição das variáveis do contexto de situação campo, relações e modo (HALLIDAY, 1989) das estórias, a fim de levantar semelhanças e diferenças entre os textos, focalizando o contexto de produção e sua recontextualização no livro didático. Essa análise também foi importante para reconhecer significados de realizações léxico-gramaticais (segundo procedimento), já que significados variam de acordo com a natureza dos contextos em que os textos são usados.

Como segundo procedimento, cada texto foi segmentado em orações, cada uma das quais foi analisada com base nas funções léxico-gramaticais do sistema de transitividade (processos, participantes e circunstâncias) (HALLIDAY, MATTHIESSEN, 2014), para identificar fases e etapas fundamentais e, assim, confirmar a instanciação do propósito sociocomunicativo e as características linguísticas que realizam o gênero. Para isso, foi utilizado o sistema de cores 
apresentado por Halliday e Matthiessen (2004), em que processos materiais foram destacados, nos textos, com a cor vermelha, relacionais com amarela, mentais com azul, existenciais com laranja, verbais com verde, comportamentais com roxo. Após, foram contabilizados os números de realizações de cada processo nas fases, etapas e no texto todo, gerando três tabelas para cada gênero (episódio e exemplum). Com recursos do Excel, foi possível gerar gráficos para melhor visualização dos resultados.

O terceiro passo foi a análise de ocorrências de afeto, julgamento e apreciação, do subsistema atitude do sistema de Avaliatividade (MARTIN; WHITE, 2005), o que possibilitou evidenciar o propósito sociocomunicativo do texto e, por conseguinte, também o gênero de texto. Para essa identificação, foram usados realçadores de texto do Word, em que o sublinhado indica avaliação do tipo afeto; o negrito, julgamento; e o itálico, apreciação. Após a contagem das ocorrências, foram produzidas tabelas que geraram gráficos para visualização dos resultados sobre as frequências de uso no corpus. .

\section{RESULTADOS}

A análise e discussão dos resultados são organizadas em três subseções: uma se refere aos resultados da análise de contexto de situação das estórias; as outras duas subseções referem-se à investigação de aspectos linguísticos do exemplum e do episódio, com foco no sistema de transitividade, associado ao sistema de Avaliatividade - especificamente o subsistema Atitude -, e sua realização na constituição e identificação das etapas, das fases e, por conseguinte, do propósito sociocomunicativo que, em conjunto, permitem reconhecer o gênero instanciado no texto.

\subsection{Análise contextual}

O corpus desta pesquisa apresenta dois tipos de contexto de situação: o de produção, em que os textos foram originalmente publicados por seus autores, e o de circulação, no caso, o livro didático, em que os textos foram reproduzidos com outros objetivos de leitura.

Em seu contexto de produção, verificou-se que as estórias, na variável campo, possuem diferenciados propósitos, algumas fazem rir (PL6E1, PL6E4, PL8E6, PL8E8, etc.), outras refletem sobre comportamentos sociais (PL6E14, 
PL6E16, PL8E21, etc.) e mais algumas apresentam afetuosamente sentimentos ou lembranças das personagens (PL6E3, PL7E5, etc.).

Há diversos contextos históricos e sociais presentes nos textos. Um deles é a Grécia Antiga (século VII a.C), com as fábulas de Esopo (PL6E15, PL7E17, PL7E18, etc.), em cenários campestres, envoltos por florestas ou casas no campo. Há também contextos mais modernos, como um sinal de trânsito, em uma anedota de Donaldo Buchweitz (PL8E6), e um bairro tumultuado, em uma piada de Elifas Andreato (PL9E13). Também, há contextos de pobreza, como o cenário do sertão de Pernambuco, permeado pela fome e sede, em um conto de Paulo Mendes Campos (PL8E9), ou, ainda, um contexto mais nacionalista, como uma praça repleta de palmeiras e melros (ave típica brasileira) no interior de Belo Horizonte, às margens do rio Doce, em um conto de Ziraldo (PL6E2).

Dessa maneira, o objetivo das estórias, em seu contexto de produção, varia conforme a época em que os textos foram produzidos. As fábulas de Esopo (PL6E15, PL7E17, PL7E18, etc.), por exemplo, tinham como propósito transmitir sabedoria de caráter moral ao homem. Por isso, animais representavam características humanas, como o leão a força, a formiga o trabalho, ou seja, valores determinantes para sustentação da sociedade aristocrática da Grécia Antiga. Já anedotas ou piadas de Buchweitz (PL8E6, PL8E7, PL8E10, PL9E12), todas publicadas na coletânea

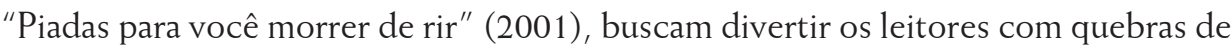
expectativas que deixam as personagens em situações inusitadas, abordando temas como família, profissões, animais, etc.

Outros textos do século XXI, como o conto de Paulo Mendes Campos (PL8E9), buscam, além de gerar humor, fazer uma crítica social sobre a população carente do sertão nordestino brasileiro. Ainda, Ziraldo, em seu conto (PL6E2), ao utilizar recursos da fauna e flora brasileira, busca exaltar a identidade nacionalista.

Na variável relações, os participantes nos textos (personagens) são fictícias, ora humanas (PL6E1, PL6E2, PL6E3, etc.), ora animais com comportamentos humanos (PL6E14, PL6E15, PL6E16, etc.). Os animais são utilizados principalmente metaforicamente nas fábulas, para ensinar algum comportamento moral. Percebemse diferenças sociais provenientes dos papéis sociais desempenhados por eles nas estórias, atrelados novamente ao contexto histórico. Por exemplo, em uma fábula de Millor Fernandes (PL7E19), publicada no Brasil, em 1991, a distância social entre as personagens é máxima, pois há utilização de recursos interpessoais que revelam hierarquia entre as personagens, como o uso de "senhor" e "doutor" por uma mulher ao referir-se a um médico. Em outra fábula de Millor (PL7E20), a distância social é mínima, pois um tigre chega a usar a gíria "Hei velho" ao interagir com um caçador, 
demonstrando que não há hierarquia entre eles. $\mathrm{O}$ tipo de relação predominante entre as personagens, no corpus é a distância mínima, característica que condiz com a família das estórias, que, segundo Martin e Rose (2008), apresenta gêneros elementares, de linguagem menos elaborada, com o propósito de entreter o leitor.

Os participantes na interação (autor e leitor/ouvinte), como já explicitado, variam conforme a época. Esopo, escravo na Grécia Antiga no século VI a.C., contava estórias para mostrar como os seres humanos agiam para bem ou para mal; suas fábulas, que faziam parte da tradição oral, foram reunidas e escritas muito tempo depois, inspirando diversos escritores ao longo dos séculos e até hoje são lidas por adultos e crianças. . Millor Fernandes, humorista, dramaturgo, poeta, tradutor e jornalista brasileiro do século XX, criticava o poder e as forças dominantes, tendo sido, por isso, alvo frequente de censura no período da ditatura civil-militar. Buchweitz, diretor geral da editora Ciranda Cultural, promove Feiras de Livros e editoração de livros para o público infanto-juvenil e adulto.

Na variável modo, algumas estórias, apesar de aparecerem de modo escrito, eram orais em seu contexto de produção de origem, como as fábulas de Esopo (PL6E14, PL6E15, PL7E17 e PL7E18). Ele contou suas estórias na Grécia do século VII a. C., as quais foram publicadas mais tarde por escritores como Jean de La Fontaine, na França do século XVII, para fins educativos. No contexto do Livro Didático, elas aparecem também de modo escrito.

Em seu contexto de circulação, as estórias são recontextualizadas nos Livros Didáticos (doravante LDs). Nesse cenário, na variável campo, o conteúdo das estórias permanece inalterado, apenas uma estória (PL6E2) aparece no LD fragmentada (apenas o início é reproduzido no livro). O que se altera, na variável campo, é o suporte: de livros de estórias, por exemplo, os textos passam a circular nos LDs. Dessa forma, além de fazer rir, ensinar comportamentos, etc., nos LDs de Língua Portuguesa analisados, mais especificamente nos capítulos que focalizam aspectos gramaticais e discursivos, como as seções "Língua em foco", "De olho na escrita" e "Semântica e Discurso" do livro "Português Linguagens", segundo Gerhardt (2017), as estórias têm por função exemplificar conteúdos da língua mobilizados nos textos ou em atividades.

A variável relações, no contexto de circulação das estórias, também passa por algumas alterações, pois são os autores dos LDs que escolhem os textos a serem recontextualizados para fins didáticos. Nesse caso, os autores dos LDs pressupõem que os leitores das estórias sejam não só professores do Ensino Fundamental, que escolhem o material didático a ser utilizado em aula para ensino e aprendizagem de conte do EF. A distância social entre os autores dos LDs e os professores e 
estudantes que consomem os LDs é média, pois, apesar do desconhecimento dos autores dos LDs de quais alunos ou professores especificamente serão os leitores das obras, esses autores sabem que seu alvo são professores e estudantes de Língua Portuguesa, e que, para isso, precisam usar uma metalinguagem acessível a esses usuários.

Ainda quanto ao contexto de circulação, na variável modo, verifica-se que 20 textos do corpus estão na coleção "Português-Linguagens" e apenas um na coleção "Projeto Teláris - Português", com fonte citada. As estórias aparecem entre um comando para a leitura e atividades de interpretação e análise linguística. Algumas são acompanhadas de imagens, colocadas pelos autores dos LDs, servindo, em geral, para complementar o texto verbal.

A análise linguística dos textos, apresentada na sequência, corrobora o reconhecimento desse contexto e evidencia as etapas e fases dos gêneros foco deste estudo.

\subsection{Análise das instâncias de exemplum}

Para identificação das etapas e fases que constituem a Estrutura Esquemática de Gênero (EEG) do exemplum, foram analisados os tipos de oração conforme o sistema de transitividade e também os campos semânticos do subsistema de Atitude do sistema de Avaliatividade. O Gráfico 1 mostra a frequência dos tipos de orações em cada uma das etapas das instanciações de exemplum que compõem o corpus.

Gráfico 1. Realização dos tipos de orações em etapas do exemplum

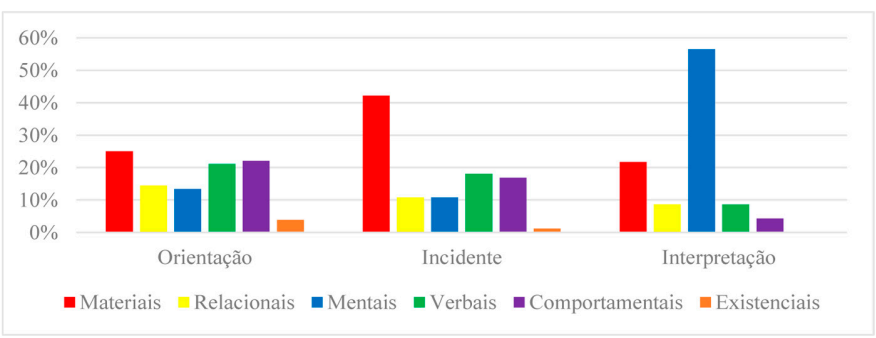

$\mathrm{Na}$ etapa Orientação dos textos que instanciam o gênero exemplum, orações materiais (30\%) e relacionais (9\%) são usadas para apresentar personagens e lugares, ocorrendo principalmente nas fases cenário e descrição. Os excertos a seguir exemplificam orações materiais e relacionais, respectivamente, usadas para representar ações ou características das personagens na etapa Orientação: 
(1) $[\ldots]$ a formiguinha que passava carregando uma folha de roseira. (PL6E14).

(2) Você é a mais traiçoeira de todas as criaturas. (PL6E16).

Ainda na etapa Orientação, identifica-se o uso de orações comportamentais (23\%), verbais (19\%) e mentais $(14 \%)$, por meio das quais são representadas atitudes de personagens que desempenham "má conduta" perante a ética social. Os excertos a seguir exemplificam cada caso.

(3) Não trabalho, pouso em todas as mesas. (PL6E14).

(4) A formiguinha arriou a carga, enxugou a testa e disse: - Apesar de tudo, não invejo a sorte das moscas. (PL6E14)

(5) Um urso passava o tempo contando como gostava dos homens. (PL6E15).

Em (3), o processo comportamental trabalho, associado à polaridade negativa não, e o processo comportamental pouso representam atitudes de alguém que leva uma vida sem muito esforço, o que é visto pela sociedade como um mau comportamento. Em (4) o processo verbal disse introduz uma citação cujo conteúdo revela uma atitude (não ser invejosa) que é aceitável e bem-vista socialmente. Em (5), o processo mental gostava evidencia a atitude supostamente afetiva do urso, que será desmentido mais adiante na estória, revelando outro mau comportamento perante a sociedade, o de ser dissimulador. Essas escolhas linguísticas representam comportamentos e características que, na etapa Orientação, são responsáveis por proporcionar as causas do Incidente (físico ou psicológico). Na etapa Interpretação, o problema é interpretado em relação a esses maus comportamentos.

Na etapa Incidente, também são recorrentes orações materiais (42\%) para construção do problema da natureza externa (física) das experiências humanas, como neste exemplo:

(6) Daí a dez minutos, um tigrão enorme meteu a cabeça na porta da tenda e gritou, com seu vozeirão: "Hei velho, você deve quinhentas pratas à viúva do outro". (PL7E20).

Em (6), a oração material "um tigrão enorme meteu a cabeça na porta da tenda" causa uma ruptura na sequência esperada para a estória - no caso, a de que o caçador trouxesse um tigre para o outro ver, e não que um tigre aparecesse sozinho na tenda. Assim, a quebra no fluxo dos eventos esperados, em que o caçador morre e o próprio tigre avisa o fato ao outro caçador, causa o Incidente. 
Numa porcentagem muito menor, também são recorrentes orações mentais (11\%) para construir problemas da natureza interna (psíquica) das experiências humanas na etapa Incidente. Por exemplo:

(7) [...] o sapo sentiu a picada mortal do escorpião. (PL6E16).

No excerto, o processo mental sentir evidencia que a natureza experiencial do problema é interna. Dessa forma, percebe-se que o problema, no gênero exemplum, pode ser de ordem tanto material quanto mental, mas sobretudo material em função da frequência maior.

Além disso, para introduzir ou evidenciar a fase problema, na etapa Incidente, é comum o uso de circunstâncias de localização que evidenciam o momento e o lugar em que o problema acontece, como em (8).

(8) Durante a travessia do rio, porém, o sapo sentiu a picada mortal do escorpião. (PL6E16).

Outro recurso usado é a polaridade negativa que, associada a um processo, indica, implicitamente, a frequência de uma ação, como no exemplo (9).

(9) Nunca, entretanto, o jardineiro deixou de regar o pé de girassol. (PL8E21).

Em (9), o adjunto negativo nunca, correlacionado a deixou representa o pressuposto de que o jardineiro sempre realizou a ação de regar o pé de girassol, apesar da rejeição da planta, revelando uma quebra da expectativa na sequência dos eventos (a de que a prática do benefício fosse cessada diante da rejeição do beneficiado).

$\mathrm{Na}$ etapa Interpretação, tendo em vista os dados do Gráfico 1, verificase a utilização recorrente de orações mentais $(57 \%)$, especificamente nas fases comentário e reflexão, conforme exemplos 10 e 11, respectivamente:

(10) O impostor promete o impossível: basta um nada para confundi-lo. (PL7E18).

(11) - Você o tratava mal, agora está arrependido? - Não, respondeu, estou triste porque agora não posso tratá-lo mal. É minha maneira de amar, ele sabia disso, e gostava. (PL8E21).

Em (10), o processo mental promete evidencia a característica mentirosa da toupeira, que é julgada por mentir para sua mãe. Em (11), o processo mental gostava revela um comportamento do girassol em relação ao jardineiro, também avaliado. 
Em menor número, também é possível verificar a utilização recorrente de orações verbais nas fases reflexão (19\%), como em (11), por meio do processo verbal respondeu, e comentário (10\%), como em (12), para introduzir o conteúdo da moral na etapa Interpretação.

(12) Minha filha - disse a mãe -, além de cega, perdeste o olfato. (PL7E18).

Em (12), um comentário é introduzido na estória por meio de uma oração verbal que representa a voz de uma das personagens na função de Dizente (a mãe) que se dirige a outra personagem na função de Vocativo (Minha filha).

O predomínio de orações mentais na etapa Interpretação evidencia que o problema da estória não foi resolvido, mas interpretado, podendo confirmar que os textos analisados instanciam o gênero exemplum. Se houvesse, nessa etapa, número maior de orações materiais, por exemplo, haveria a resolução dos problemas, pois, com a retomada do fluxo normal dos eventos, construídos por orações materiais, o problema seria resolvido, constituindo, assim, uma narrativa.

Contudo, apenas a utilização de orações mentais na etapa final não permite identificar que o gênero instanciado seja um exemplum, pois o gênero episódio também possui uma complicação não resolvida. Por outro lado, a essa complicação aparece uma reação na etapa final, cuja construção também utiliza processos mentais. Nesse aspecto, a análise do sistema de Avaliatividade, mais especificamente do subsistema de Atitude, possibilitou distinguir com mais precisão um gênero do outro.

O Gráfico 2 mostra a frequência de ocorrências de Atitude em cada uma das etapas das instanciações de exemplum que compõem o corpus.

Gráfico 2. Ocorrências de Atitude em etapas do exemplum

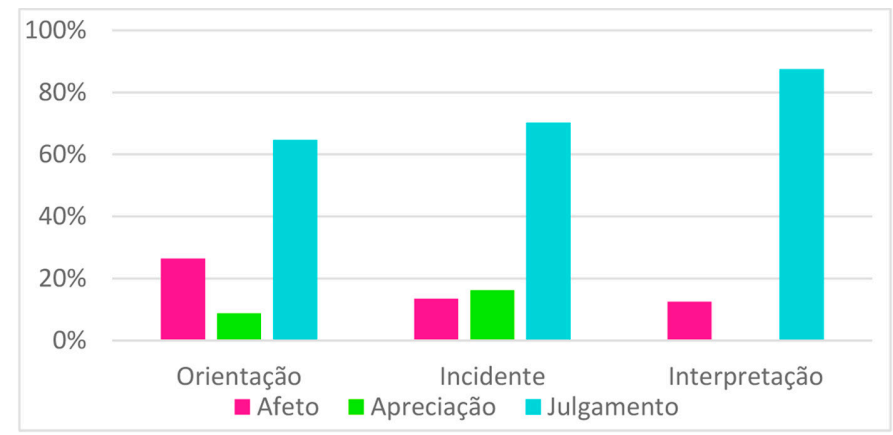


O Gráfico 2 mostra a recorrência, em todas as etapas, de avaliações de julgamento (67\%) para cumprir o propósito fundamental do gênero: julgar comportamentos. Exemplos:

(13) $[\ldots]$ - Apesar de tudo, não invejo a sorte das moscas. São malvistas. Ninguém as estima. Toda gente as enxota com asco. E o pior é que têm um berço degradante: nascem nas esterqueiras. (PL6E14).

(14) Você é a mais traiçoeira das criaturas. Se eu te ajudar, você me mata em vez de me agradecer. (PL6E16).

Em (13), na voz da formiguinha, o uso do processo comportamental invejar, junto à polaridade negativa expressa pelo não, evidencia avaliação de julgamento sobre seu próprio comportamento, de não invejar a "boa" vida da mosca, ou seja, a formiguinha busca parecer madura, sensata frente ao comportamento de vida da mosca. Também, por meio do Atributo malvistas, a formiguinha julga o caráter das moscas, que possuem uma vida boa por meios ilícitos. Em (14), o Atributo traiçoeira, utilizado pelo sapo, é responsável por julgar o comportamento do escorpião, bem como a escolha do termo criatura, e não animal, por exemplo, que seria menos agressivo dentre as possibilidades de referência ao escorpião.

O gráfico também demonstra que as ocorrências de julgamento são essencialmente maiores na etapa Interpretação. Como Martin e Rose (2008) explicam, essa etapa é responsável por interpretar moralmente algum comportamento apresentado pelas personagens ao logo da história, fazendo julgamentos, como na moral exemplificada:

(15) Mais vale ter pena dos vivos que respeito com os mortos. (PL6E15).

Em (15), quem conta a estória faz um julgamento sobre a atitude do urso, animal que, apesar de dizer que não perturba ou estraçalha suas caças, realiza a morte delas. Assim, o contador procura evidenciar que o urso é, de qualquer forma, um animal mau dentro de seu habitat.

Avaliações de afeto (20\%) e apreciação (13\%) ocorrem em menor número no gênero exemplum, se comparadas com as avaliações de julgamento. Esse resultado comprova que o gênero não prioriza sentimentos e emoções ou a estética de pessoas, objetos ou instituições, mas sim uma atitude diante do comportamento dos indivíduos, que podem ser beneficiados ou prejudicados pelas consequências de suas próprias ações. 


\subsection{Análise das instâncias de episódio}

O Gráfico 3, a seguir, demonstra a frequência dos tipos de orações nas etapas das instanciações de episódio no corpus deste estudo.

Gráfico 3. Realização dos tipos de orações em etapas do episódio

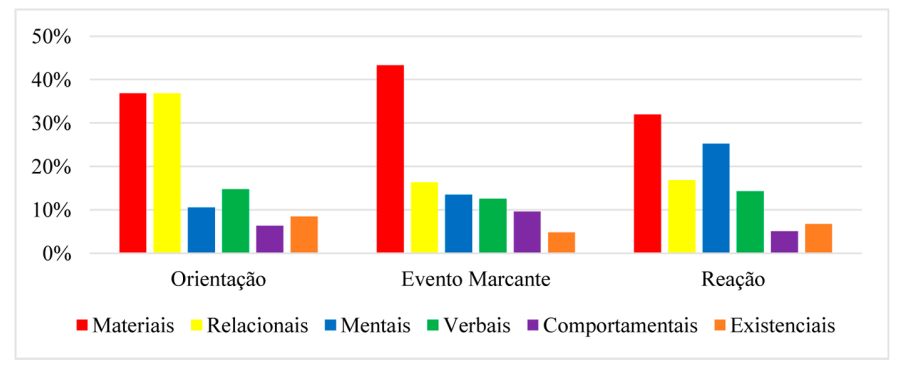

De acordo com os dados apresentados no gráfico, é possível identificar que, na etapa Orientação do gênero episódio, assim como no gênero exemplum, é fundamental a realização de orações materiais (49\%) e relacionais (25\%). De igual modo, apresentam personagens, espaços, atividades e suas respectivas características e são responsáveis pela construção das fases cenário e descrição. Exemplos:

(15) A rua é pequena,

meio torta,

o carro passa rápido,

as casas ficam quietas,

janelas nem piscam. (PL6E5).

(16) Chovia bá três dias sem parar e o campo de futebol estava completamente inundado. (PL6E4).

O processo material passa evidencia uma atividade que acontece no cenário (uma rua) e o processo relacional é introduz caracterização do cenário da estória.

Além disso, as instanciações de episódio apresentaram número relevante de orações existenciais (8\%) para apresentar o cenário (lugares, personagens, atividades), como no exemplo (17) a seguir, diferentemente do exemplum, que apresentou, além das orações relacionais e materiais, maior número de orações comportamentais (23\%) nessa etapa.

(17) Na minha rua há um menininho doente. (PL6E3). 
O trecho (17) evidencia a apresentação de um personagem, na fase cenário da etapa Orientação, por meio do processo existencial bá. A considerável utilização de orações existenciais pode estar relacionada à apresentação das fragilidades das personagens, que existem em condições adversas.

$\mathrm{Na}$ etapa Evento Marcante do episódio, foi possível verificar, assim como na etapa intermediária do exemplum, um grande número de orações materiais $(46 \%)$, as quais constituem a fase problema.

(18) Ele o havia deixado num galho de árvore para fazer uma coisa qualquer (que era melhor fazer sem seu amigo). Foi quando começou o furacão. (PL6E2).

Em (18), o processo material bavia deixado evidencia a causa de parte do problema da estória (a perca do pássaro num dia de muito vento).

Ademais, a etapa Evento Marcante, assim como na etapa Incidente do exemplum, é evidenciada por circunstâncias de localização no tempo ou polaridades negativas, como "mas", responsáveis pela quebra da expectativa ou por sinalizar o acontecimento do problema na estória. Exemplo:

(19) Outro dia nasceu uma flor na calçada

fiquei olhando até enjoar.

Depois a flor secou, esqueci. (PL7E5).

Em (19), a circunstância de localização no tempo outro dia sinaliza um momento específico da estória, proporcionando o campo para a realização do problema. Outro exemplo:

(20) Mas tu mesmo disse que tem sexo masculino e feminino. (PL8E8).

No trecho (20), a polaridade negativa mas, associada ao dizer, instancia o problema discursivo da definição da palavra "sexo".

$\mathrm{Na}$ etapa Reação, é possível visualizar que há incidência de orações verbais $(33 \%)$, relacionais $(18 \%)$ e mentais $(16 \%)$. Elas são comuns para realização da fase reação. Exemplos:

(21) O capitão de uma das equipes não concordou:

- Com tudo alagado não vai dar.

- vai dar sim - disse o juiz, pode escolher o campo. (PL6E4).

(22) Ficou furioso, mas justamente naquele momento o sinal abriu. (PL8E6). 
(23) Ele só pensa em gramática. (PL8E8).

O trecho (21) exemplifica, por meio do processo verbal dizer, a reação afirmativa de do juiz na estória. O trecho (22) exemplifica, por meio do processo relacional ficou, associado ao Atributo furioso, a reação de um motorista em relação ao problema de um menino ter vendido um jornal antigo a ele. Em (23), também é apresentada a reação do pai em relação a à atitude do garoto, mas agora por meio de uma oração mental, representada pelo processo pensa.

Ainda na etapa Reação, é possível perceber a incidência de orações materiais (32\%), demonstrando que a reação também pode ocorrer no nível material, ou seja, das experiências externas, e não apenas no nível mental, interno. Exemplo:

(24) - Chega! Vai brincar, vai.

O garoto sai e a mãe entra. (PL8E8).

Em (24), a saída de um personagem e a entrada do entro revelam uma reação, no caso, de insatisfação do garoto e de preocupação da mãe.

Novamente, apenas o fato da utilização de orações mentais e/ ou materiais com figura de experiência interna, na etapa final, não permite identificar que o gênero instanciado seja o episódio, pois o gênero exemplum também possui uma complicação não resolvida, mas reagida na etapa final, cuja construção também utiliza processos mentais. Nesse momento, novamente, a partir da análise do Sistema de Avaliatividade, mais especificamente do subsistema de Atitude, foi possível distinguir um gênero do outro.

O Gráfico 4 mostra a frequência de ocorrências de Atitude em cada uma das etapas das instanciações de episódio que compõem o corpus.

Gráfico 4. Ocorrências de Atitude em etapas do episódio

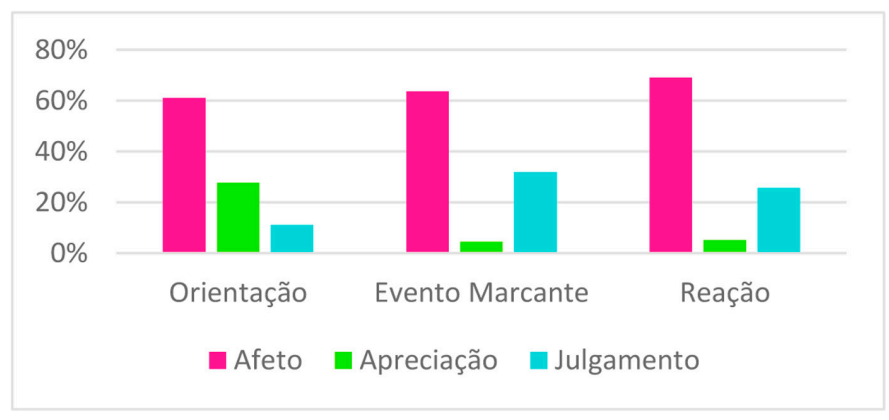


No gênero episódio, são comuns avaliações de afeto (61\%), ao longo de todo o texto, que têm por função ajudar na construção do propósito do gênero: compartilhar emoções. Exemplos:

(25) seu passo-preto foi um grande amigo em sua velbice. (PL6E2).

(26) Na minha rua bá um menininbo doente.

Enquanto os outros partem para a escola,

Junto à janela, sonbadoramente,

Ele ouve o sapateiro bater sola. (PL6E3).

Em (25), o Atributo grande amigo realiza uma avaliação de afeto do menino em relação ao seu pássaro (passo-preto). Em (26), O Atributo doente, atribuído ao menino, bem como o uso do diminutivo, conferem ao segmento menininho doente avaliação de afeto. $\mathrm{O}$ advérbio sonbadoramente também avalia afetivamente o sonho do menino.

Avaliações de julgamento (24\%) e apreciação (15\%) ocorrem em menor número no episódio, se comparadas com as avaliações de afeto nesse gênero. Esse resultado comprova que o episódio não prioriza avaliações sobre o comportamento, que admiramos ou criticamos, aprovamos ou condenamos, ou sobre a estética de materiais, objetos ou instituições, mas sim sentimentos e emoções resultantes de eventos marcantes vivenciados pelas personagens.

\section{CONSIDERAÇÕES FINAIS}

O objetivo deste trabalho foi apresentar características linguísticas que instanciam outros gêneros de texto, além da narrativa, usados para contar estórias, encontrados em Livros Didáticos de Língua Portuguesa dos anos finais do Ensino Fundamental, a partir da verificação do propósito sociocomunicativo e da EEG dessas instanciações. A seguir, apontamos algumas conclusões sobre a constituição desses gêneros na coleção "Português Linguagens", de Cereja e Magalhães (2012) e "Projeto Teláris - Português", de Borgato, Bertin e Marchezi.

Quanto à análise contextual dos textos que constituem o corpus, é possível destacar que os diferentes cenários culturais em que se encontravam os autores dos textos, em seus contextos de produção, influenciam os propósitos sociocomunicativos das estórias: o episódio aparece instanciado em textos nomeados no LD como narrativa, crônicas, piadas, anedotas, poemas, conto, ou 
simplesmente "texto". O exemplum aparece instanciado em textos nomeados no LD como fábulas e também "textos".

Verificou-se que as instanciações de exemplum e episódio analisadas possuem uma etapa que se repete, a Orientação, além do uso de funções léxico-gramaticais com finalidades semelhantes, como processos materiais e relacionais para apresentar personagens, atividades e espaços. Ademais, processos materiais foram recorrentes na etapa Incidente, no exemplum, e na etapa Evento Marcante, para introduzir a fase problema nesses gêneros. Essas características que aproximam os textos permitem agrupá-los na mesma família de gêneros, no caso, a das estórias, na qual compartilham um mesmo propósito geral: envolver ou entreter o leitor.

Ao mesmo tempo, verificou-se que as respostas aos problemas, nos textos, são diferentes: ora uma Reação, evidenciada pela frequência de processos mentais e verbais e ocorrências de avaliações de afeto, ora uma Interpretação, com recorrência de processos comportamentais e avaliações de julgamento. Essas características que distanciam os textos permitem distingui-los quanto aos seus propósitos específicos, quais sejam: compartilhar uma reação e julgar comportamentos. Assim, podem ser classificados como gêneros distintos: episódio e exemplum, respectivamente.

Além disso, com o que foi possível realizar nesta pesquisa, podemos reconhecer os traços linguísticos que evidenciam as etapas, as fases e o propósito que constroem os gêneros. Também, é possível dizer que o gênero é evidenciado por essas marcas, num processo de via de mão dupla. Assim, este trabalho pode contribuir com a área de estudos linguísticos pautados na Linguística Aplicada e com os estudos em Linguística Sistêmico-Funcional desenvolvidos em contexto específico escolar brasileiro. Especificamente, pode auxiliar os primeiros passos sobre investigações de gêneros na perspectiva sistêmico-funcional no que diz respeito a aspectos linguísticos e contextuais de episódios e exempla instanciados em textos usados em LDs brasileiros.

Ademais, destaca-se a importância da consciência sobre os usos da linguagem para alcançar propósitos em contextos específicos. De acordo com Gouveia (2009), o uso consciente da gramática possibilita a construção de blocos de sentidos (textos), que instanciam os gêneros que circulam na sociedade. Desse modo, ao ter consciência sobre os significados produzidos pela linguagem que circula em determinados meios sociais e seus padrões de instanciação, estudantes, dentro e fora da escola, têm mais chances de desenvolver autonomia e obter sucesso nas interações sociais com desenvolvimento crítico e responsável nos contextos de que participar. 
Assim, a resposta à pergunta presente no título deste artigo é não, nem toda estória é uma narrativa. Estórias, como já apontado por Martin e Rose (2008) e reafirmado neste trabalho, são uma família que engloba os gêneros narrativa, episódio, exemplum, relato, observação e notícia. Possuem o mesmo propósito geral de entreter o leitor, porém, a partir de distintas características linguísticas e estruturas esquemáticas, realizam propósitos sociocomunicativos mais específico e, por isso, podem ser classificados distintamente. Com isso, queremos mostrar que, embora sutis, há diferentes maneiras de contar uma estória, dependendo do propósito sociocomunicativo que se pretende alcançar.

\section{REFERÊNCIAS}

BASTOS, L. C.; BIAR. L. A. (2017). Análise de narrativa e práticas de entendimento da vida social. Delta, 97 - 126. Disponível em: < http://www.scielo.br/pdf/delta/ v31 nspe/1678-460X-delta-31-spe-00097.pdf>. v. 31, n. 4, p. 00-00, 2 Acesso em: 18 de janeiro de 2019 .

BORGATTO, A. T.; BERTIN, T.; MARCHEZI, V. (2012). Projeto Teláris: Português. São Paulo: Ática, v. $6^{\circ}$ ano.

BRASIL (1997). Ministério da Educação. Secretaria de Educação Fundamental. Parâmetros Curriculares Nacionais: Língua Portuguesa. Brasília: MEC/SEF.

CEREJA, W. R.; MAGALHÃES, T. C. (2012). Português: Linguagens. São Paulo: Saraiva, v. $6^{\circ}$ ano

CHRISTIE, F.; DEREWIANKA, B. (2008). School Discourse. New York: Continuum.

COSTA, R. P.; CATELLAN, J. C. (2010). Uma proposta metodológica de ensino de língua portuguesa a partir do gênero discursivo "piada". In: BRASIL. O professor PDE e os desafios da escola pública paranaense. Artigo PDE 2010: Governo do Estado do Paraná

COELHO, N. N. (2010). Panorama bistórico da literatura infantil: das origens indo-europeias ao Brasil contemporâneo. Barueri: Manole.

CUNHA, M.A.F.; SOUZA, M.M. (2011). Transitividade e seus Contextos de Uso. Coleção Leituras Introdutórias em Linguagem, v. 2. São Paulo: Cortez.

CUNHA, M. I. (1997). Conta-Me Agora!: As Narrativas como Alternativas Pedagógicas na Pesquisa e no Ensino. Revista da Faculdade de Educação. São Paulo: FE/USP. v. 23, n. 1-2, 
p. 185-195, jan./dez. Disponível em: < http://www.scielo.br/scielo.php?script=sci arttext\&pid $=$ S0102-25551997000100010 $>$. Acesso em: 14 de novembro de 2018.

FUZER, C. (Org). (2016). Ateliê de Textos: atividades de leitura detalhada. Santa Maria: UFSM, CAL.

FUZER, C.; WEBER, S. (2018). Chapeuzinho vermelho em três versões: análise de gênero na perspectiva Sistêmico-Funcional. Revista Fórum Linguístico, UFSC, Santa Catarina, v. 15, n. 3, p. 3210 - 3223. Disponível em: < https://periodicos.ufsc.br/index.php/ forum/article/view/1984-8412.2018v15n3p3210>. Acesso em: 20 de janeiro de 2019.

FUZER, C.; GERHARDT, C. C.; WEBER, S. (2016). Etapas e fases da narrativa em O Pequeno Polegar: análise de gênero na perspectiva sistêmico-funcional. Cadernos do IL, Porto Alegre, n. 52, p. 162-181, dez. Disponível em: <https://seer.ufrgs.br/ cadernosdoil/article/view/67867>. Acesso em: 15 de novembro de 2018.

FUZER, C.; CASTRO, M. C.; GERHARDT, C. C. (2016). Análise do gênero episódio na perspectiva da Escola de Sydney em contexto escolar brasileiro. $31^{\text {a }}$ Jornada Acadêmica Integrada. Anais... Santa Maria. Disponível em: < https://portal.ufsm. br/jai/trabalho/trabalho.html? action=anais $>$. Acesso em 10 de outubro de 2018.

FUZER, C.; GERHARDT, C. C.; CARGNIN, E. S. (2015). Levantamento de gêneros em Livro Didático de Língua Portuguesa. In: Congresso da Associação de Linguística Sistêmico-Funcional da América Latina. 11, 2015, Santa Maria. Anais... Santa Maria, UFSM. Disponível em: <http://w3.ufsm.br/lincs/alsfal/contextoseducacionais. html>. Acesso em: 10 jun.

FUZER, C.; CABRAL, S.R.S. (2014). Introdução à Gramática Sistêmico-Funcional em Língua Portuguesa. Campinas, SP: Mercado de Letras.

GERHARDT, C. C. (2017). Investigações dos gêneros episódio e exemplum na perspectiva SistêmicoFuncional em livros didáticos de língua portuguesa do Ensino Fundamental. 2017. 234 p. Dissertação (Mestrado em Letras) Universidade Federal de Santa Maria.

GOUVEIA, C. A. (2009). Texto e gramática: uma introdução à Linguística SistémicoFuncional. Matraga, Rio de Janeiro, v. 16, n. 24, p. 13-47 jan./jun. Disponível em: $<$ https://www.e-publicacoes.uerj.br/index.php/matraga/article/view/27795>. Acesso em: 13 de agosto de 2018. 
GOUVEIA, C. A.. (2013). Os géneros escolares e a disciplinarização do saber: contributos da linguística sistémico-funcional para a promoção do sucesso escolar. SEMINÁRIO INTERNACIONAL EM LETRAS, 8, 11 a 14 jun., Santa Maria, RS. Minicurso. [não publicado].

HALLIDAY, M. (1985 [1994]). An introduction to functional grammar. London: Arnold.

HALLIDAY, M.; HASAN, R. (1989 [1985]). Language, Context and Text: aspects of language in a social-semiotic perspective. Oxford: Oxford University Press.

HALLIDAY, M.; MATTHIESSEN, C. M. I. M. (2004 [2014]). Introduction to functional grammar. London: Arnold.

LABOV, W.; WALETZKY, J. (1967). Narrative analysis: oral versions of personal experience. In: HELM, J. (Ed.). Essays on the verbal and visual arts: proceedings of the 1966 Annual Spring Meeting of the American Ethnological Society. Seattle/London: University of Washington Press, p. 12-44.

MARTIN, D. (1997). Modelling Context: A Crooked Path of Progress in Contextual Linguistics. In: Genre Studies. Shanghai: Shanghai Jiao Tong University Press. p. 187-222.

MARTIN, D. (2000). Grammar meets genre. Reflections on the "Sydney School". The Journal of the Sydney University Arts Association. v. 22, p. 47-95.

MARTIN, D.; WHITE. (2005). The Language of Evaluation: appraisal in English. Basingstoke [England]: Palgrave Macmillan.

MARTIN, D.; ROSE, D. (2008). Genre Relations: Mapping Culture. London: Equinox.

MARTINO, L. M. S. (2016). De um eu ao outro: narrativa, identidade e comunicação com a alteridade. Revista Parágrafo, v. 4, n. 1, p. 41-49. Disponível em: < http:// revistaseletronicas.fiamfaam.br/index.php/recicofi/article/view/377>. Acesso em: 14 de maio de 2018.

MELO, E. N. M. (2017). Uma investigação funcionalista da estrutura argumental preferida e da acessibilidade de referentes em narrativas escritas destinadas ao público infantil. 2017. 105 p. Dissertação (Mestrado em Letras) - Universidade Presbiterna Mackenzie.

OCHS, E. (1997). Narrative. In: VAN DIJK, T. A. Discourse as structure and process. London: Sage Publications. p. 185-206. 
PLUM, G. A. (2004 [1988]).Text and contextual conditioning in spoken English: a genre-based approach. Unpublished PhD Thesis, University of Sydney.

ROSE, D. (2014). Selecting and Analysing Text (Book 2). In: ROSE, J. Reading to Learn. Sydney: p. 1-45.

ROSE, D.; MARTIN, J. R. (2012). Learning to Write, Reading to Learn: Genre, Knowledge and Pedagogy in the Sydney School. London: Equinox.

ROTHERY, J. (1990). Story Writing in Primary School: Assessing Narrative Type Genres. Unpublished PhD thesis, Department of Linguistics, University of Sydney.

ROTHERY, J.; STENGLIN, M. (2000). Entertaining and instructing: exploring experience through story. In: CHRISTIE, F.; MARTIN, J. Genre and Institutions. London and New York: Continuum. p. 231-265.

SOUZA, M. (2016). Ciclo de Ensino e Aprendizagem, gramática e contexto: um estudo do uso dos processos em "estórias" na escola. 2016. 166 p., Dissertação (Mestrado em Letras) - Universidade de Pernambuco, Nazaré da Mata, PE.

VIAN JR. O; SOUZA, A.A.; ALMEIDA, F.P.S.D.P. (Orgs). (2010). A linguagem da Avaliação em Língua Portuguesa: estudos sistêmico-funcionais com base no Sistema de Avaliaitivade. São Carlos: Pedro \& João Editores.

VYGOTSKY, L. S. (2007 [1984]). A formação social da mente. Tradução de José Cipolla Neto, Luís Silveira Menna Barreto, Solange Castro Afeche. São Paulo: Martins Fontes.

Recebido: 23/04/2019

Aceito: 18/12/2019

Publicado: 28/01/2020 